\title{
A CAPITANIA DO ESPÍRITO SANTO E Á DEFESA DO RIO DE JANEIRO.
}

No entusiasmo de tantas comemorações festivas do IV Centenário do Rio de Janeiro, não pode permanecer desprezado o valor da contribuição sincera e forte da Capitania do Espírito Santo, na defesa do Brasil, contra os franceses e conseqüente fundação da nova Cidade.

De início, para os colonizadores da Capitania, séria preocupação surgiu, com os franceses, que rondavam a costa. Veio, por isso, da Bahia de Todos os Santos, grande remessa de armas e munições, porque Antônio Cardoso de Barros, que regressara de uma excursão aos portos do Sul, escrevera a ElRei, a 30 de abril de 1551, com o aviso de

"que andavam muitos franceses, por esta costa" (1).

Dizemos outra remessa, porque, a 14 de setembro de 1550 , o Provedor-Mor da Bahia passara um Mandado, para que o almoxarife dos armazéns e mantimentos da Cidade do Salvador, Cristóvão de Aguiar, fornecesse a Francisco de Oliveira

"a artilharia e munições abaixo declaradas - "A saber, um falcão de metal com o seu reparo a duas Câmaras, e uma chave e setenta pelouros e um barril de pólvora de bombarda, e dois quintais de ferro, as quais coisas eram por estar a dita Capitania para a defesa, etc." (2).

Antes, pelo Mandado, de 4 de março de 1550 já haviam sido entregues

(1). - Notícias Antigas do Brasil. Anais da Biblioteca Nacional. LVII, 5.

(2). - Documentos Hist6ricos. XIV, 93. 
$$
-100-
$$$$
\text { "quarenta espadas guarnecidas de suas bainhas" }
$$

A 23 de março de 1550, outro Mandado foi expedido, para a entrega das

"coisas seguintes (ao Capitão e Governador do Espírito Santo): - seis meios berços, e um falcão de metal com suas chaves com três Câmaras, para cada peça de seis meios berços, e duas para o falcão, e cento e cincoenta pelouros; cento e vinte, para meios berços, vinte para cada um e trinta para o falcăo, e um quintal de pólvora, e dez lanças, e dez piques e quarenta espadas" (4).

Vasco Fernandes Coutinho deveria pagar, pelos preços dos armazéns do Reino.

Ao referir-se ao Govêrno de Duarte da Costa, diz Pôrto Seguro que

"os franceses apareceram, no Brasil, em maior fôrça que nunca, e chegaram a estabelecer-se, no Rio de Janeiro. Os gentios do Espírito Santo e de Pernambuco cobraram alento e vinham assolando e ameaçando as povoações". (5).

Já, em 1551, chegara ao Espírito Santo Cristóvão Cabral, Capitão de uma caravela da esquadrilha pertencente a Pero de Góis. Voltava do Rio de Janeiro, quando se encontrou, em alto mar, com uma nau francesa, que lhe antepôs combate. Não podendo vencê-la, fugira, e afastara-se, até aportar em Vitória, onde foi prêso e depôsto do comando (6).

A 10 de novembro de 1555 , chegou ao Rio de Janeiro o Vice-Almirante Nicolau Durand de Villegaignon (7), para estabelecer uma colônia francesa. Fortificou-se, na entrada da Barra; numa ilha que, posteriormente, recebeu o seu nome e, até agora, o conserva. Conquistou logo a amizade dos índios, que o auxiliaram, depois, na defesa de sua desejada posse.

A Capitania do Espírito Santo, sempre cobiçada pelos invasores do Brasil, recebeu logo o sinal ameaçador, com a expedição comandada por Bois le Conte. Fundearam todos os

(3). - Ibldem. XXXVII, 41.

(4). - Mbidem. XVII, 42.

(5). - Pórto Seguro, História Geral do Brasil. I, 375

(6). - Basflio Daemon, A Província do Espírito Santo. 64.

(7). - Pórto Seguro, História Geral do Brasil, II, 375. 
navios, a conveniente distância, e dispararam alguns tiros, para atrair os indígenas à praia.

Vimos acima que já estavam, nesse tempo, os franceses estabelecidos no Brasil, porque, informando pelos seus patrícios, que vinham comerciar com os índios, Nicolau Durand de Villegaignon preparou uma armada e veio, com muitos soldados. Na Ilha de Serigipe, defendido, ou protegido pelo Forte de Coligny, escavou um paiol. Faltaram-lhe, porém, água e outras condições de subsistência.

Havia o Pe. Brás Lourenço, que substituira ao Pe. Afonso Brás, no Espírito Santo, concordado em trazer-se para a $\mathrm{Ca}$ pitania a tribo dos temiminós, contrária aos tamoios e, portanto, aos franceses, no Rio de Janeiro. Tratava-se de índios que viviam errantes, ao Norte de Niterói, onde os emissários de Vasco Fernandes Coutinho e Brás Lourenço negociaram a aliança com o cacique Maracaiaguaçú, ou Grande Gato. Divergem os cranistas, se houve convite a essa tribo, ou dela tivesse partido o apêlo de agasalho, em conseqüência da perseguição que lhe moviam os franceses. A situação era de penúria martirizante!... Consta que o Grande Gato mandara seu filho ao Espírito Santo, pedir transporte.

$$
\begin{aligned}
& \text { "Ele e sua mulher, e seus filhos e os mais dos seus } \\
& \text { se queriam fazer cristãos". }
\end{aligned}
$$

E' o que registra o Pe. Luís da Grã, em carta de 24 de abril de 1555, escrita do Espírito Santo (8).

Partiram de Vitória quatro embarcações, para o transporte dos novos aliados, cuja recepção, impressionante, foi presenciada pelo referido sacerdote, que estava de passagem na Ilha. Instalaram-se, primeiramente, nas proximidades da Vila, e dêles se ocupou o Pe. Brás Lourenço (9). Iniciaram ali a cultura de cereais, motivo do nome Capixaba, dado ao lugar.

Perante a notícia da aliança dos temiminós, no Espírito Santo, o Vice-Almirante e Cavaleiro de Malta promoveu investigações, na Capitania, e confiou essa emprêsa ao seu sobrinho Bois le Conte, que partiu da França, a 19 de novembro de 1556 , e chegou ao Rio de Janeiro a 16 de março de 1557, com o refôrço de três navios: Petite Roberge, no qual vinha o Capitão,

(8). - Pe. Serafim Leite, História da Companhia de Jesus no Brasil, I, 23.

(9). - Novas Cartas Jesuíticas, 189-191. 
Grande Roberge e Rosée, e trezentos homens, além de catorze padres calvinistas. Jéan de Lery diz que vieram duzentas e noventa pessoas, inclusive sete meninos, que deveriam aprender a língua dos naturais, e cinco moças, aos cuidados de uma matrona.

\author{
"De vê-las, - conta-se, ficaram embasbacados os tu- \\ pinambás" (10).
}

Discordam os cronistas se, de fato, chegou ao Espírito Santo uma nau, ou expedição. Discordam igualmente nas datas. José Texeira de Oliveira registra o fato em 1558. Basílio Daemon a 26 de fevereiro de 1557. Pôrto Seguro diz que Bois le Conte chegou ao Rio de Janeiro a 16 de março do mesmo ano (11) . O certo é que desembarcou no Rio de Janeiro um refôrço de, aproximadamente, trezentos homens, em três navios equipados por conta da Corôa Francesa, e comandados por Bois le Conte. Vinham na comitiva dois teólogos calvinistas, além de Jéan de Lery, como auxiliar, e que nos deixou inapreciável narrativa, na qual nos baseamos para esclarecimento das controvérsias. As naus eram, de fato, Grande Roberge, com cento e vinte pessoas; a Petite Roberge, com oitenta e a Rosée, com noventa, ou "quase noventa". Uma interessante nota era a presença de cinco moças, aos cuidados de uma senhora, para se casarem, no Brasil (12).

Esse refôrço partiu da França a 19 de novembro de 1556, e chegou ao Rio de Janeiro, a 7 de março de 1557. Não podia, portanto, estar, no Espírito Santo, em fevereiro dêsse ano; mas, passou por aqui, antes de chegar à Guanabara. No confrônto de algumas datas, vemos que a expedição de Bois le Conte avistou a terra brasileira a 26 de fevereiro de 1557 (13), o que está de acôrdo com o registro de Basílio Daemon:

"Apareceu, ao Norte de Vitória, a 26 de fevereiro de 1557; a expedição francesa comandada por Bois le Conte"...

Estava, portanto, a caminho para o Rio de Janeiro.

De Vitória mandaram Simão de Azeredo e Mestre Nau francês, residente na Vila - a bordo, investigar das intençōes dos singulares viajantes (14). Recebidos e agasalhados, conta-

(10). - Roberto Southey, Hístória' do Brasil, I.

(11). - Pôrto Seguro, História Geral do Brasil, I, 361.

(12). - Ibidem.

(13). - Cartas Avulsas, 210.

(14). - Ibidem. 
ram coisas fantásticas, existentes na Ilha e, segundo as "Cartas Avulsas", de um homem faziam cem; de um barco, muitos; de quatro canoas, quatrocentas; de um padre, um mosteiro; até que os franceses, atônitos, amedrontados, levantaram âncora, ao amanhecer, e foram-se, com os informantes, ainda a bordo. Jéan de Lery, hàbilmente, omite essa passagem; refere-se apenas à permuta de víveres, com anzóis, espelhos e outras mercadorias.

Rumaram os franceses para o Sul; mas, no Itapemirim, onde pretendiam fazer carregamento de pau-brasil, sofreram combate dos indios, que lhes tomaram

"uns vinte homens, uma chalupa, uma ferriria e muito resgate e roupas" (15).

II

Mem de Sá partiu da Bahia de Todos os Santos, a 16 de janeiro de 1560, para a arriscada emprêsa de combater os invasores no Rio de Janeiro. Trazia oito embarcações, soldados, armas e munições. $\mathrm{Na}$ passagem pelas capitanias de Ilhéus e Pôrto Seguro, foi recebendo novos contingentes. No Espírito Santo, porém, a contribuição foi maior, apesar de estarem os moradores temerosos dos índios e dos mesmos franceses (16). Rocha Pombo e outros autores registram que, nessa viagem do Governador Geral, o famoso Maracaiaguaçú incorporou-se à expedição. E, de acôrdo com Simão de Vasconcelos, o chefe Ararigbóia foi igualmente ao Rio de Janeiro nessa ocasião. Roberto Southey fala na atuação de Ararigbóia nessa passagem histórica:

"Um índio convertido, que no batismo recebera o nome de Martim Afonso, tão honrosamente se đistinguiu, nesse feito, que, em recompensa, teve uma pensão e a Ordem de Cristo".

$\mathrm{E}$, no comentário do texto, lemos:

"Ararigbóia era o seu nome indigena e capitaneava os valentes tupiminós, que ocupavam o país a que hoje denominamos de Província do Espírito Santo".

(15). 一 Ibidem.

(16). - Basilio Daemon, A Provincia do Espírito Santa. 
O Governador Geral do Brasil permaneceu alguns dias, no Espirito Santo, pois sòmente a 21 de fevereiro chegou à Guanabara .

O valioso auxílio dado pela Capitania do Espírito Santo à defesa do Rio de Janeiro despertou, entretanto, uma represália. dos invasores. Em fins de 1561, entraram na Baía da Vitória duas naus francesas, completamente armadas, e colocaram-se. fronteiras à Vila, em ponto de poucos moradores, que residiam. em casas cobertas de palha, e que ficaram aterrados!

Ciente do caso, o Capitão Belchior de Azeredo reuniu os índios flecheiros e os escravos; dirigiu-se ao Colégio dos Jesuítas; na igreja de São Tiago todos rezaram. Acompanhados pelo. $\mathrm{Pe}$. Brás Lourenço, que ia na frente, com o estandarte daquele Santo; foram perseguir o inimigo. Rumaram todos ao lugar onde estavam os franceses. Deu-se terrível combate, com disparos de tiros e bestas. O padre a todos animava. Viam-no; em tôda a parte, a encorajar os combatentes, até que os franceses. foram vencidos e obrigados a fugir, com inúmeras perdas, perseguidos sempre pelo Capitão-Mor e sua gente: portuguêses e. naturais da terra e escravaria. Postos em debandada, embarcaram em suas naus e, em seguida, sairam, barra-a-fora.

De acôrdo com os relatos históricos,

"nem um balaço fêz dano nos da povoação nem a ela",

o que significa sorte excepcional, pois muitos tiros foram trocados, durante as quatro horas de combate. E a pelêja decidiu-se;

$$
\begin{aligned}
& \text { "graças a um tiro certeiro, ao lume d'água em uma } \\
& \text { das naus", }
\end{aligned}
$$

e ao inesperado aparecimento de um navio que, de São Vicente, ia para o Reino.

Batidos, na Ilha da Vitória, procuraram carregar as embarcaçōes, com pau-brasil, em um pôrto do Sul; mas, os índios tomaram-lhes uma chalupa e fizeram sete a oito cativos (17).

Em carta que o Pe. Miguel Tôrres escreveu, a 10 de junho. de 1562, temos a confirmação dêsse fato:

"Este ano passado, depois que o Governador Mem de. Sá destruiu a fortaleza do Rio de Janeiro, foi esta Capitania mui combatida dos franceses, os quais, entrando neste pôrto, com duas naus mui grandes e bem artilhadas,

(17). - Cartas Avulsas, 263. 
se puseram defronte desta povoação, coisa de causar assás terror, por serem os moradores poucos e as casas cobertas de. palha e sem fortaleza, etc.".

Basílio Daemon observa que o ataque devia ter-se dado, em Vila Velha; mas, o certo é que o estandarte de São Tiago era de Vitória, onde estava a igreja consagrada ao mesmo Santo. E a Vila Velha tinha forte, desde o início da colonização. Deuse, portanto, o fato, na sede do Govêrno.

Ia intensificar-se ainda mais a colaboração do Espírito Santo na defesa do território brasileiro. Em 1561 parte, na galé São Tiago, para o Rio de Janeiro, com gente e munições, Belchior de Azeredo, a fim de auxiliar Estácio de Sá, no mesmo combate aos franceses.

Estácio o reenviou ao Espírito Santo, no navio Santa Clara,

"porque era pessoa a quem se podia confiar tôda a causa do serviço de Deus e de Sua Alteza, para que indo à Capitania provesse das causas necessárias, ‘ije no Rio de Janeiro fazia mister, e que trouxesse todos e quaisquer navios que lá encontrasse, ou fôsse ter, ainda que fôssem os da Capitania e Armada, que carregasse nêles o que fôsse provimento, para a nova Cidade, e tomasse a gente precisa, para os navios, mandando assentar em sôl-

1 do do dia em que tomasse, fazendo-lhes pagamento à custa da Fazenda Real, para o que tomasse todo o dinheiro dos feitos que, na Capitania do Espírito Santo, houvesse, não achando os de Sua Alteza, mandando na Provisão de 1561, aos Capitães-Mores e Senhores dos refıridos navios que em tudo e por tudo lhes obedessem e viessem ter com êle, em sua companhia e conșerva, no Jiio de $\mathrm{Ja}$ neiro" (18).

Vencidos os franceses, Mem de Sá mandou seu sobrinho Estácio de Sá, em nau tomada ao inimigo, levar a notícia à Côrte, em Portugal. Mas, apenas retirados aquêles invasores, dos quais alguns se refugiaram no Continente, surgiu no Sul do Brasil outro perigo para o domínio português. Várias tribos, simpáticas aos franceses, reuniram-se e constituiriam a poderosa Confederação dos Tamoios (1562) para impedir a fundação de uma Cidade, no Rio de Janeiro, e destruir São Vicente e a

(18). - José Marcelino, Ensaio sôbre História e Estatística da Província do Espirito Santo. 
Vila de São Paulo. Seus chefes eram Jaguanhara e Araraí. Nóbrega e Anchieta (1563) conseguiram a paz, auxiliados pelo chefe Tibiriçá, que repetiu os silvícolas, dirigidos por Araraí, a 10 de julho de 1562 (19). A êsse propósito o poeta Domingos de Magalhães escreveu um poema indianista, verdadeira epopéia, com o título "Confederação dos Tamoios".

Tratados com benevolência pelos franceses, tinham os índios justo motivo da referida simpatia. Seguiam, aliás, os invasores norma bem diversa dos portuguêses, o que levou Paul Bert a escrever:

"Nós não somos colonizadores?! - Perguntai aos indígenas de todos os países, por onde passamos, que pensam da raça alegre, benevolente, sem arrogância, apta a adotar os costumes dos vencidos, mais capaz ãe produzir que de destruir" (20).

Estácio de Sá, que regressara ao Brasil, em 1563, com uma armada de seis caravelas, o galeão São João e uma nau de carreira da fndia, chamada Santa Maria, a Nova, à qual juntou o Governador Geral mais seis navios, que pôde reunir, seguiu para o Rio de Janeiro, onde chegou a 6 de fevereiro de 1564 (21). O povo se opusera à viagem de Mem de Sá, na expedição, o Ouvidor-Geral Brás Fragoso, o Comendador de São Jorges Paulo Dias Adôrno, com uma galeota própria de dez pares de remos e outros capitães.

Chegou a expedição ao Espírito Santo, para tomar reforços. E, segundo o Barão do Rio Branco, Belchior de Azeredo seguiu igualmente, para o Rio de Janeiro. Distinguiu-se ali quando os expedicionários aprisionaram uma nau francesa.

Mas uma vez, portanto, coube ao Espírito Santo contribuir para a defesa do Brasil contra os franceses, porque essa expedição partiu da Bahia de Todos os Santos, em escalas, em diversos portos e chegou, assim, à Capitania, onde recebeu a melhor acolhida. Conseguiram mesmo os expedicionários a adesão do cacique Ararigbóia, comandante de duzentos índios flecheiros. Bem sortido de mantimentos, munições bélicas e gente, seguiu o Capitão Estácio de Sá para a Guanabara, onde logo, em combate, tanto quanto o referido Belchior de Azeredo, distinguiu-se o guerreiro íncola.

(19). - Rio Branco, Efemérides brasileiras.

(20). - Oliveira Lima, Formaçao da Nacionalidade Brastleira.

(21). - Rio Branco, Efemérides Brasileiras. 
"A Partida de Ararigbóia" constituiu o tema de um grande quadro de Levino Fânzeres, que existe na Assembléia Legislativa do Espírito Santo.

Começou, portanto, Vasco Fernandes Coutinho Filho o seu govêrno com generoso auxílio à defesa da terra brasileira, e conquistou geral simpatia. Mesmo porque, nesse mesmo ano, assumira o pôsto de Donatário da Capitania (1564) .

Durante algum tempo, Ararigbóia muito auxiliou o Govêrno, contra os franceses e os tamoios; chegou até a reunir quatro mil arcos, em campo de combate. Agia sempre com valorosa coragem. Recebeu por isso, de El-Rei, como recompensa, o título de Cavaleiro de Cristo e uma tença de $12 \$ 000$, além de uma sesmaria de uma légua, em São Lourenço de Niterói. Fundou ali uma aldeia, com seus parentes e companheiros (22). O núcleo prosperou e, segundo o cronista Basílio Daemon, em 1587, Ararigbóia vivia ainda, na Aldeia de São Lourenço. Mas, o certo é que, em 1575, foi dos que visitaram - Governador do Sul, Dr. Antônio Salema. Conta-nos Frei Vicente do Salvador que, tendo a referida autoridade lhe oferecido uma cadeira, o famoso cacique sentou-se e cruzou as pernas. Advertido, então, quanto à falta de cortezia, nessa posição, diante do Governador, respondeu, logo:

"Se tu souberas quão cansadas eu tenho" as pernas, das guerras em que servi a El-Rrei, não estranhavas darlhes agora êste pequeno descanso; mas, já que me achas pouco cortesão, eu me vou embora para minha aldeia, onde não curam dêsses pontos, e não mais tornarei à tua Côrte".

E; de fato, não mais voltou.

Perante o registro do valioso auxílio prestado pela Capitania ao Govêrno Geral do Brasil, Varnhagem foi conduzido a ressaltar a vitória de Estácio de Sá,

"com o refôrço que conseguira do Espírito Santo, e que foi considerável" (23).

Ao chegar ao Rio de Janeiro, Estácio reconheceu o vultoso reduto, que teria de enfrentar; foi a São Vicente proverse de mais recursos. Chegou à Guanabara a 28 de fevereiro de 1565 e fortificou-se junto ao Pão de Açúcar. A $1 .^{\circ}$ de março lançou os fundamentos, ou primeiros alicerces, da Cidade de São Sebastião do Rio de Janeiro.

(22). - Basílio Daemon, A Provincia do Espirito Santo.

(23). - Pórto Seguro, História Geral do Brasil, I, 394. 
Em maio do mesmo ano, José de Anchieta, que viajava à Bahia de Todos os Santos para receber a ordenação sacerdotal, esteve no Espírito Santo, a fim de visitar as aldeias e a Casa Colegial. Mediante sermões, confortou o povo martirizado pela varíola. Chegou à Cidade do Salvador a 15 de outubro e relatou ao Governador Geral do Brasil a situação embaraçosa em que se achava seu sobrinho Estácio, no Rio de Janeiro, necessitado de reforços, para enfrentar os franceses e os tamoios.

Estácio, que partira de Bertioga a 20 de janeiro de 1566, veio ao Espírito Santo em fevereiro buscar gente, munições e mantimentos. Demorou-se alguns dias e voltou ao Rio de Janeiro, onde chegou em princípios de março. Fortificou-se na Praia Vermelha e, no ataque naval aos tamoios e aos franceses, venceu-os galhardamente. Belchior de Azeredo comandou a pelêja com uma flotilha de canoas. No combate que se verificou perto de Paquetá, a 13 de julho do mesmo ano, morreu Guaixara, o cacique dos tamoios (24).

Pelos seus feitos, em diversas passagens agora referidas, mereceu Belchior de Azeredo o pôsto de Capitão do navio São Jorge pela Provisão de 3 de abril de 1566.

"Em tôdas as guerras do Rio de Janeiro, sempre se distinguiu, pelo valor, intrepidez e bom senso, alcançando muitas vitórias sôbre os indigenas e sôbre os franceses" (25).

Pelo Alvará de 27 de novembro de 1566 foi o seu valor recompensado ainda com a mercê de Cavaleiro Fidalgo.

\section{III}

Em face do relato de José de Anchieta, Mem de Sá tratou logo de aprestar algumas embarcações, com tropas e mantimentos, que partiram da Bahia em novembro de 1566 . Vieram, então, o próprio Governador Geral, o Bispo Dom Pedro Leitão e o Pe. Inácio de Azevedo, como Visitador Geral dos Jesuítas e os Pes. José de Anchieta, Luís da Grã, Antônio Ro-

(24). - Rio Branco, Efemérides Brasileiras.

(25). - José Marcelino, Ensaio sôbre História e Estatística da Província do Espirito Santo. 
drigues, Baltazar Fernandes e Antônio Rocha (26). A esquadrilha estava sob o comando de Cristóvão de Barros.

No Espírito Santo a expedição recebeu dos povoadores forte e vultoso refôrço, além de-duzentos índios flecheiros, cedidos pelo Donatário Vasco Fernandes Coutinho Filho. Mas, embora assim aprestada, sòmente em fins de dezembro. (ou princípios de janeiro seguinte) deixou o Espírito Santo, porque, na Vila da Vitória, Mem de Sá esteve muito doente, o que explica a demora no prosseguimento da viagem, de modo que, pelo Natal, Anchieta que estivera no Salvador quase dois anos, para se ordenar, celebrou missas na igreja de São Tiago. 1567.

A expedição chegou ao Rio de Janeiro a 18 de janeiro de

Diz o Pe. Pero Roiz, em Anchieta, que o Governador Geral levou Ararigbóia. Mas, o cacique temiminó já estava no Rio de Janeiro, pois, em 1564, na passagem de Estácio de Sá para o Sul, Ararigbóia seguiu com duzentos índios flecheiros, graças aos esforços de Vasco Fernandes Coutinho Filho.

$\mathrm{Na}$ História Militar do Espírito Santo descrevemos essas passagens com as devidas minúcias.

Ferido no rosto por uma flecha envenenada, Estácio de Sá faleceu a 20 de fevereiro. Mem de Sá transferiu a Cidade recém-fundada, para o Morro do Castelo.

Após a morte de Estácio, Mem de Sá continuou a pelêja, sempre auxiliado por Ararigbóia e sua gente. Instalado na Aldeia de São Lourenço, o índio partiu mais tarde, com Salvador Corrêa de Sá, para combater os franceses em Cabo Frio, onde salvou das ondas o Capitão, durante um combate, em pequenas embarcações.

Tempos depois, assaltada sua aldeia pelos tamoios, venceu-os numa batalha de loucos, em pleno negror da noite, onde o sangue dos índios misturou-se com o dos franceses.

Foi, como prêmio dêsse feito, que recebeu o Hábito de Cristo, um vestuário do seu uso o pôsto de Capitão da sua aldeia e a tença de $12 \$ 000$.

Em 1568, Ararigbóia recebeu a sesmaria de uma légua, ao longo do mar, e duas, para o sertão, ainda em São Lourenço.

Muito justamente, Sílvio Salema escreveu que Ararigbóia deve ser considerado o Primeiro General Carioca, porque, nascido na Ilha de Paranapuan, atualmente do Governador, foi o

(26). - Basilio Daemon, A Província do Espirito Santo, 86. 
comandante dos temiminós que defenderam o solo do seu berço (27).

Reina muita confusão quanto às viagens de Ararigbóia e Maracaiaguaçú. $O$ certo é que o Grande Gato não mais aparece nos registros históricos, após a viagem com o Governador Geral em 1560. Dado porém o valor dos índios flecheiros do Espírito Santo, não se pode duvidar que Ararigbóia tenha participado de duas expedições. Sua lembrança, entretanto, revive sempre na História e na Literatura. Decantados e enaltecidos os seus feitos permanecem inesqueciveis no Espírito Santo. Vejamos esta parte de um poema escrito por Orminda Escobar Gomes que transcrevemos com a devida vênia:

Partiu Ararigbóia..., assim nos diz a lenda.

Flecheiros seus fiéis seguiram, p'ra tremenda

Batalha a se ferir, na grande Guanabara.

Intimorato, sim, lembrava Guairará.

Seu povo chefiando, além, no Paraná;

Pois conquistar queria aquela jóia rara!

Lutou, supremo chefe, até, por fim, vencer.

Nas águas da baía, após o alvorecer,

Igaras deslisavam, mansamente. . . Ao forte,

Aos plainos, morros, ilhas, praias e alcantis,

Voavam flechas mil, visando hordas hostis

Dos feros coligados, espalhando a morte.

Por justa decisão, o Vice-Rei doou

A Ararigbóia, o herói, e aos índios, que levou.

A nobre Praia Grande... alegre e original.

Orgulho de Coutinho, era êle o mais audaz

De quantos possuia o seu rincão feraz,

P'ra glória do Brasil, - a Pátria sem rival! (28) .

Outras notícias confusas aparecem, quanto ao nascimento e à morte do chefe temiminó. Concordamos, entretanto, que tivesse, mesmo, nascido na sua querida Paranapuan, visto como transferida a tribo em 1555 para a Capitania do Espírito Santo, não podia, em 1560, Ararigbóia ter desenvolvimento preciso para ser um grande guerreiro. Além disso, em 1556, quando o Pe. Brás Lourenço fundou com Maracaiaguaçú a Aldeia Velha (Santa Cruz), coube a Ararigbóia a fundação de outra Aldeia, - a

(27). - Diário de Notícias, 30 de abril de 1961.

(28). - A "Gazeta". Vitória. 12 de setembro de 1954. 
de São João de Carapina, enquanto os tupiniquins se organizavam na Aldeia de Conceição da Serra. Todos sob a direção do mesmo jesuíta.

Antes de vir para a Capitania do Espirito Santo, Ararigbóia esteve em São Vicente, para auxiliar a luta contra os tamoios e os franceses.

"Aqui se fêz grande soldado", - escreve , Pe. Pero Roiz, em Anchieta. Veio, então, para o Espírito Santo, onde "foi o principal de uma aldeia",

continua o mesmo biógrafo. Perante o seu valor, na defesa da Vila da Vitória, contra os franceses, Mem de Sá o levou, na expedição ao Rio de Janeiro.

Registram alguns cronistas que Ararigbóia morreu afogado, na Baía da Guanabara. Mas, o referido Pero Roíz, cuja obra data de 1607, descreve os últimos instantes de Martim Afonso (Ararigbóia),

"com muita fé e devoção". "falando a São Sebastião, para que o ajudasse a vencer os inimigos invisiveis, assim como o ajudara a vencer os visíveis. $\mathbf{E}$, depois de receber os sacramentos e o da Extrema Unção, chamou seus parentes, fêz testamento, e repartiu com êles uma grande herança, não de coisas temporais, que êle não tinha, nem os índios estimam, mas, de maravilhosos conselhos". E conclui o biógrafo de Anchieta, o relato sôbre a morte de Ararigóbia: - "Deu sua alma a Deus, com muita consolação sua e edificação dos presentes". 